\title{
Isobavachalcone exerts anti-proliferative and pro-apoptotic effects on human liver cancer cells by targeting the ERKs/RSK2 signaling pathway
}

\author{
BINBIN LI ${ }^{1,2^{*}}$, NANSONG XU ${ }^{2 *}$, ZHENG WAN ${ }^{3}, \mathrm{LI} \mathrm{MA}^{4}, \mathrm{HUAHUI} \mathrm{LI}^{2}$, WEIJIE CAI ${ }^{2}$, \\ XIUMEI CHEN ${ }^{2}$, ZUNNAN HUANG $^{2}$ and ZHIWEI HE ${ }^{1,2}$ \\ ${ }^{1}$ Department of Pathophysiology and ${ }^{2}$ China-American Cancer Research Institute, Guangdong Medical University, \\ Dongguan, Guangdong 523808; ${ }^{3}$ Medical College of Xiamen University, Xiamen, Fujian 361000; \\ ${ }^{4}$ Faculty of Laboratory Medicine, Guangdong Medical University, Dongguan, \\ Guangdong 523808, P.R. China
}

Received September 20,2018; Accepted March 19, 2019

DOI: $10.3892 /$ or.2019.7090

\begin{abstract}
Aberrant activation of the extracellular signal-regulated kinases (ERKs)/ribosomal S6 kinase 2 (RSK2) signaling pathway is frequently determined in various human tumor types, including liver cancer, and has been considered as a promising target for cancer chemoprevention and therapy. In the present study, using computer-aided virtual screening and molecular docking, isobavachalcone (IBC), a natural chalcone compound, was identified to be an ATP-competitive inhibitor targeting ERK1/2 and RSK2. Cell Counting Kit-8, EdU incorporation and colony formation assays were used to detect the effects of IBC on cell viability and proliferation, and the results demonstrated that IBC effectively inhibited the proliferation of liver cancer HepG2 and Hep3B cells, whereas it had no notable cytotoxic effect on immortal liver L02 cells. Flow cytometric analysis and western blotting further revealed that IBC caused significant levels of apoptosis on liver cancer cells via the caspase-dependent mitochondria pathway. The computer prediction was confirmed with pull-down and in vitro
\end{abstract}

Correspondence to: Professor Zunnan Huang or Professor Zhiwei He, China-American Cancer Research Institute, Guangdong Medical University, 1 Xincheng Road, Dongguan, Guangdong 523808, P.R. China

E-mail: zn_huang@yahoo.com

E-mail: zhiweihe688@yahoo.com

"Contributed equally

Abbreviations: IBC, isobavachalcone; ERK1/2, extracellular signal-regulated kinase 1/2; RSK2, ribosomal S6 kinase 2; MAPK, mitogen-activated protein kinase; EGF, epidermal growth factor; CREB, cAMP response element-binding protein; ATF1, activating transcription factor 1; AP-1, activating protein-1

Key words: isobavachalcone, liver cancer, extracellular signal-regulated kinase 1/2, ribosomal S6 kinase 2, proliferation, apoptosis kinase assays, in which IBC directly bound with ERK1/2 and RSK2, and dose-dependently blocked RSK2 kinase activity in liver cancer cells. Treatment of HepG2 or Hep3B cells with IBC significantly attenuated epidermal growth factor-induced phosphorylation of RSK2 and resulted in the reduced activation of its downstream substrates including cAMP response element-binding protein, activating transcription factor 1, histone $\mathrm{H} 3$ and activating protein-1. Enforced RSK2 expression in L02 cells could increase the effect of IBC on suppressing cell growth. Conversely, knockdown of RSK2 reduced the inhibitory effect of IBC on HepG2 cell proliferation. Overall, the present data indicated that ERKs/RSK2 signaling serves a pivotal role in IBC-induced suppression of liver cancer cells and that IBC may be a potential therapeutic candidate for human cancer with elevated ERKs/RSK2 activity.

\section{Introduction}

Primary liver cancer is predicted to be the sixth most common neoplasm and the fourth leading cause of cancer-associated mortality globally in 2018 , responsible for $\sim 782,000$ mortalities annually (1). Additionally, 75-85\% of primary liver cancer cases occurring globally are hepatocellular carcinoma (1). Etiologically, the carcinogenesis of liver cancer is a complex, multistep and multifactorial process involving environmental risk factors, genetic derangement and aberrant signal transduction (2). The mitogen-activated protein kinase (MAPK) pathways are implicated in various cellular processes, including cell survival, proliferation, differentiation and apoptosis. The components of MAPK signaling have been indicated to be promising targets in developing novel chemoprevention and targeted therapies for cancer (3). It was notable that the aberrant activation of the Raf/mitogen-activated protein kinase kinase (MEK)/extracellular signal-regulated kinases (ERKs) pathway serves a pivotal role in the development, progression and invasiveness of liver cancer and is associated with poor survival rate and multidrug resistance $(4,5)$. Sorafenib and BAY86-9766, inhibitors targeting the Raf/MEK/ERKs pathway, have been evaluated in clinical trials and have 
demonstrated promising results in the treatment of unresectable liver cancer $(6,7)$. However, as this protein kinase pathway is central to numerous signaling networks, including phosphoinositide 3-kinase (PI3K)/Akt, Janus kinase/signal transducer and activator of transcription and protein kinase $\mathrm{C} /$ nuclear factor- $\kappa \mathrm{B}$, blocking Raf/MEK/ERKs signaling may result in a number of adverse events and drug resistance $(3,8)$. Sorafenib suppresses the MAPK signaling pathways, but partially induces the activation of PI3K/Akt signaling, which is responsible for sorafenib-promoted invasion and metastasis in liver cancer (9). Therefore, it is proposed that blocking a subset of downstream functions of the MAPK pathways may be a more effective strategy with fewer side effects.

Ribosomal S6 kinase 2 (RSK2), a member of the p90RSK protein family, is a direct substrate kinase of ERK1/2 and is activated in response to oncogenic signals and/or growth factor stimuli (10). Alterations of the ERKs pathway have been well documented in human liver cancer. Increased expression and functional activity of ERK1/2 were observed in primary liver cancer, compared with the adjacent non-cancerous tissues $(11,12)$. Constitutively activated ERK1/2 was demonstrated to be required for the proliferation and invasion of live cancer cells $(13,14)$. Hepatitis B and C viruses, the two most common causes of liver cancer, express viral proteins that activate the ERKs signaling cascade $(15,16)$. The ERKs/RSK pathway was demonstrated to mediate ethanol-induced proliferation of HepG2 cells (17). Collectively, these observations implied that aberrant activation of the ERKs/RSK2 pathway may be an important molecular event in hepatocarcinogenesis, and it is desirable that the ERKs/RSK2 signaling axis becomes the subject of target-based therapies for liver cancer.

In the last few decades, natural products extracted from plants have attracted notable attention as potential anticancer agents possessing efficacy and safety (18). Considering the increasing drug resistance, the broad inhibition of multiple signaling pathways or targets, rather than a single specific target, may represent a more promising strategy for cancer treatment (19). Recently, computational biology has been frequently applied for virtual screening of multiple-target inhibitors, with the advantage of selecting a smaller number of lead compounds in a large database for biological testing, while avoiding expensive and time-consuming experiments (20). In the present study, using structure-based virtual screening and molecular docking, $>500$ traditional Chinese medicine compounds available from TianJin ShiLan Technology Company were screened for identification of potential inhibitors targeting the ERKs/RSK2 pathway. The results demonstrated that isobavachalcone (IBC), a natural chalcone compound, can be bound inside the ATP binding pocket of ERK1/2 and RSK2 with high affinity, implicating that IBC may be an ATP-competitive inhibitor targeting ERK1/2 and RSK2. The antitumor activity of IBC against liver cancer cells and its inhibitory effect on the ERKs/RSK2 signaling pathway were further evaluated, in the hope of providing novel insight into the potential application of IBC as a chemotherapeutic agent for liver cancer.

\section{Materials and methods}

Virtual screening and molecular modeling. The three-dimensional structures of RSK2 and ERKs were obtained from the PDB databank (http://www.rcsb.org/) [RSK2 N-terminal kinase domain, PDB ID 3UBD (21); RSK2 C-terminal kinase domain, PDB ID 4D9U (22); ERK1 kinase domain, PDB ID 4QTB; and ERK2 kinase domain, PDB ID 4QTA (23)]. Prior to virtual screening, the raw PDB structures were converted into an all-atom, fully prepared receptor model structure with the Protein Preparation Wizard module in Schrödinger (24). Subsequently, the docking receptor grids were created by Glide's Receptor Grid Generation (25). The grid boxes and centers were set to default with the co-crystal ligands in their ATP binding sites.

The structures of $>500$ traditional Chinese medicine compounds, which were downloaded from the PubChem Compound database (http://www.ncbi.nlm.nih.gov/pccompound/), were downloaded and a small compound database referred to as the ShiLan database was built using the LigPrep module (26). These compounds were available from TianJin ShiLan Technology Company (Tianjin, China). Glide was used to run the extra precision (XP)-docking screening of this ShiLan database targeted to two protein receptor structures (3UBD and 4D9U) $(27,28)$. The screening processes outputted two rank lists of nearly 50 compounds each. The compound IBC (CID5281255) appeared in each list, and was manually selected for further experimental tests.

Flexible ligand-protein docking was performed using the Induced Fit Docking (IFD) Module (29) in Schrödinger to assess the possible binding modes between ERKs/RSK2 and IBC. The induced fit docking can capture the possible conformational changes in receptor active site upon ligand binding. During IFD, the grid box and center for each receptor structure were set to default with the co-crystal ligand in its active binding site. Docking of IBC using its LigPrep's minimized structure into each receptor structure was also performed with Glide in XP mode (28). The binding pose with the lowest docking score was considered as the correct binding structure. The docking structures for each of the ERKs/RSK2-IBC complexes were generated using Maestra (30) in Schrödinger.

Reagents and antibodies. IBC (98\% purity) was purchased from Tianjin ShiLan Technology Company, and then it was dissolved in dimethyl sulfoxide (DMSO; $100 \mathrm{mM}$ stock solution). CNBr-activated Sepharose 4B and epidermal growth factor (EGF) were purchased from Sigma-Aldrich (Merck KGaA, Darmstadt, Germany). The primary antibodies were purchased from the following companies: Mouse monoclonal antibodies against p53 (cat. no. 2524; 1:1,000) and caspase-9 (cat. no. 9508; 1:1,000), rabbit monoclonal antibodies against cleaved caspase-9 (cat. no. 7237; 1:1,000), caspase-7 (cat. no. 12827; 1:1,000), cleaved caspase-7 (cat. no. 8438; 1:1,000), caspase-3 (cat. no. 9665; 1:1,000), cleaved caspase-3 (cat. no. 9664; 1:1,000), poly ADP-ribose polymerase (PARP; cat. no. 9542; 1:1,000), ERK1/2 (cat. no. 5695; 1:2,000), phospho-ERK1/2 (Thr202/Tyr204; cat. no. 4370; 1:1,000), phospho-RSK2 (Ser227; cat. no. 3556; 1:1,000) and Flag tag (cat. no. 14793; 1:1,000), and rabbit polyclonal antibodies against RSK2 (cat. no. 9340; 1:1,000), stress-activated protein kinase/c-Jun NH2-terminal kinase (SAPK/JNK; cat. no. 9525; 1:1,000), histone H3 (cat. no. 9715; 1:1,000) and phospho-histone H3 (Ser10) (cat. no. 9701; 1:1,000) purchased from Cell Signaling Technology, Inc. (Danvers, 
MA, USA); mouse monoclonal antibodies against mouse double minute 2 homolog (MDM2; cat. no. sc-13161; 1:500), RSK2 (cat. no. sc-9968; $10 \mu \mathrm{l}$ ) and $\beta$-actin (cat. no. sc-8432; 1:1,000) purchased from Santa Cruz Biotechnology, Inc. (Dallas, TX, USA); rabbit polyclonal antibodies against cAMP response element-binding protein (CREB; cat. no. ab31387; $1: 1,000)$ and activating transcription factor 1 (ATF1; cat. no. ab225880; 1:1,000), and rabbit monoclonal antibodies against phospho-CREB (Ser133; cat. no. ab32096; 1:1,000) and phospho-ATF1 (Ser63; cat. no. ab76085; 1:1,000) purchased from Abcam (Cambridge, MA, USA); mouse monoclonal antibodies against B-cell lymphoma 2 (Bcl-2; cat. no. 610538; 1:1,000) and Bcl-2 associated X protein (Bax; cat. no. 610982; 1:1,000) purchased from BD Transduction Laboratory (BD Biosciences; Becton, Dickinson and Company, Franklin Lakes, NJ, USA). Dylight 680-conjugated anti-mouse IgG (cat. no. 610-144-002; 1:10,000) and Dylight 800-conjugated anti-rabbit IgG (cat. no. 611-145-002; 1:10,000) secondary antibodies were purchased from Rockland Immunochemicals, Inc. (Limerick, PA, USA).

Cell culture and transfection. The human liver cancer cell lines HepG2 and Hep3B and the normal immortalized liver cell line L02 were obtained from American Type Culture Collection (Manassas, VA, USA). HepG2 and Hep3B cells were maintained in Dulbecco's modified Eagle's medium (DMEM; Thermo Fisher Scientific, Inc., Waltham, MA, USA) supplemented with $10 \%$ fetal bovine serum (FBS), $100 \mathrm{mg} / \mathrm{ml}$ streptomycin, $100 \mathrm{IU} / \mathrm{ml}$ penicillin at $37^{\circ} \mathrm{C}$ in an incubator containing $5 \%$ $\mathrm{CO}_{2}$, and L02 cells were cultured in DMEM with 20\% FBS. Cells freshly revived from cryopreservation were maintained and cultured for $\leq 8$ weeks, as aforementioned. Activating protein-1 (AP-1) luciferase reporter vector was provided by Dr ArndKieser (Helmholtz Zentrum München, Munich, Germany). The pCMV3-C-Flag-RSK2 (pCMV3-RSK2) vector and pCMV3-C-Flag (pCMV3) control vector were obtained from Sino Biological Inc. (Beijing, China). To construct the short hairpin RNA (shRNA) vector targeting RSK2 (shRSK2) and the scramble shRNA control vector (shCtrl), the mU6pro vector was digested with $X b a \mathrm{I}$ and $B b s \mathrm{I}$. The annealed synthetic primers (shRSK2, sense, 5'-TTTGAAGGCAGATCCTTCCCA GTTTCAAGAGAACTGGGAAGGATCTGCCTTTTTTT-3', and antisense, 5'-CTAGAAAAAAAGGCAGATCCTTCCCAG TTCTCTTGAAACTGGGAAGGATCTGCCTT-3'; and shCtrl, sense, 5'-TTTGACTACCGTTGTTATAGGTGTTCAAGA GACACCTATAACAACGGTAGTTTTTT-3', and antisense, 5'-CTAGAAAAAAACTACCGTTGTTATAGGTGTCTCTTG AACACCTATAACAACGGTAGT-3') were then introduced into the mU6pro vector (31). The recombinant plasmids were confirmed by DNA sequencing. L02 cells $\left(5 \times 10^{5}\right.$ cells/well) or HepG 2 cells ( $4 \times 10^{5}$ cells/well) were seeded in 6-well plates and cultured to $60-70 \%$ confluence. Then, pCMV3-RSK2 $(3 \mu \mathrm{g})$, shRSK2 $(3 \mu \mathrm{g})$ and their corresponding controls were transiently transfected into cells with jetPEI ${ }^{\mathrm{TM}}$ DNA transfection reagent (Polyplus-Transfection SA, Illkirch, France), according to the manufacturer's protocols. After being transfected for $24 \mathrm{~h}$, cells were used for subsequent experimentation.

Cell viability assay. HepG2, Hep3B or L02 cells were seeded into 96 -well plates at a density of $3 \times 10^{3}$ cells/well, and then incubated with $5,10,20$ or $40 \mu \mathrm{M}$ IBC for 24 or $48 \mathrm{~h}$ at $37^{\circ} \mathrm{C}$. Cell viability was determined with a Cell Counting Kit-8 (CCK-8; Dojindo Molecular Laboratories, Inc., Kumamoto, Japan) assay. A total of $10 \mu \mathrm{l}$ CCK- 8 solution was added to each well and cells were incubated for $2 \mathrm{~h}$ at $37^{\circ} \mathrm{C}$. The absorbance was measured at a wavelength of $450 \mathrm{~nm}$ using a Synergy 2 Multi-Mode Microplate Reader (BioTek Instruments, Inc., Winooski, VT, USA). The half-maximal inhibitory concentration $\left(\mathrm{IC}_{50}\right)$ of IBC was calculated by Probit analysis using SPSS 16.0 software (SPSS, Inc., Chicago, IL, USA).

EdU incorporation assay. Cell proliferation was assessed using a Cell-Light EdU DNA Cell Proliferation kit (Guangzhou RiboBio Co., Ltd., Guangzhou, China). HepG2 or Hep3B cells were seeded into 96 -well plates at a density of $3 \times 10^{3}$ cells/well, and then incubated with 10 or $20 \mu \mathrm{M}$ IBC for $48 \mathrm{~h}$ at $37^{\circ} \mathrm{C}$. Following treatment with IBC, cells were exposed to $50 \mu \mathrm{M}$ EdU for $2 \mathrm{~h}$ at $37^{\circ} \mathrm{C}$, and then fixed with $4 \%$ formaldehyde for $15 \mathrm{~min}$ and permeabilized with $0.5 \%$ Triton X-100 for $15 \mathrm{~min}$ at room temperature. Subsequently, cells were incubated with $100 \mu \mathrm{l} 1 \mathrm{X} \mathrm{Apollo}{ }^{\circledR}$ reaction cocktail for $30 \mathrm{~min}$ at room temperature, followed by Hoechst $33342(5 \mu \mathrm{g} / \mathrm{ml})$ for $30 \mathrm{~min}$ at room temperature in the dark. The stained cells were imaged under a fluorescence microscope (Olympus Corporation, Tokyo, Japan) at a magnification of $\mathrm{x} 200$, and the EdU positive ratio was calculated as (EdU-labeled cells/Hoechst-stained cells) $\mathrm{x} 100 \%$.

Colony formation assay. HepG2 or Hep3B cells were seeded in 6-well plates at a density of 500 cells/well and cultured with DMEM complete medium containing 5 or $10 \mu \mathrm{M}$ IBC for 2 weeks at $37^{\circ} \mathrm{C}$. The cell colonies were fixed with methanol for $15 \mathrm{~min}$ at room temperature and then stained with $0.5 \%$ crystal violet for $15 \mathrm{~min}$ at room temperature. The number of colonies containing $\geq 50$ cells was counted under an inverted optical microscope at a magnification of $\mathrm{x} 40$.

Analysis of cell cycle and apoptosis. HepG2 or Hep3B cells were starved in serum-free DMEM medium for $24 \mathrm{~h}$ at $37^{\circ} \mathrm{C}$ and treated with 10 or $20 \mu \mathrm{M} \mathrm{IBC}$ for another $48 \mathrm{~h}$ at $37^{\circ} \mathrm{C}$. Subsequently, cells were harvested with trypsin and fixed with $70 \%$ ice-cold ethanol at $4^{\circ} \mathrm{C}$ overnight. The fixed cells were stained via incubation with $10 \mu \mathrm{g} / \mathrm{ml}$ propidium iodide (PI) and $100 \mu \mathrm{g} / \mathrm{ml}$ RNase for $30 \mathrm{~min}$ at room temperature in the dark. For the apoptosis analysis, cells were treated with 10 or $20 \mu \mathrm{M}$ IBC for $48 \mathrm{~h}$ at $37^{\circ} \mathrm{C}$ and stained with Annexin V-fluorescein isothiocyanate and PI (Nanjing KeyGen Biotech Co., Ltd., Nanjing, China) for $15 \mathrm{~min}$ at room temperature in the dark, according to the manufacturer's instructions. All of the samples were analyzed using a FACS Calibur flow cytometer with Cell Quest software version 3.0 (BD Biosciences; Becton, Dickinson and Company).

Protein extraction and western blotting. HepG2 or Hep3B cells were harvested and total protein was extracted using Radioimmunoprecipitation Assay lysis buffer (Beyotime Institute of Biotechnology, Haimen, China) with phenylmethane sulfonyl fluoride (PMSF). The isolation of histone protein was performed as described previously (32). Protein concentration was determined using a bicinchoninic acid kit (Pierce; 
Thermo Fisher Scientific, Inc.). Equal amounts of total protein $(50 \mu \mathrm{g})$ or histone protein $(20 \mu \mathrm{g})$ were resolved by 10 or $15 \%$ SDS-PAGE, respectively, and transferred to polyvinylidene fluoride membranes (EMD Millipore, Billerica, MA, USA). The membranes were incubated with blocking buffer (PBS with $5 \%$ non-fat milk and $0.1 \%$ Tween-20) for $1 \mathrm{~h}$ at room temperature, and then probed with specific primary antibodies overnight at $4^{\circ} \mathrm{C}$. Subsequently, the membranes were incubated with the species-appropriate infrared-dye-conjugated secondary antibodies for $2 \mathrm{~h}$ at $4^{\circ} \mathrm{C}$, and then protein bands were visualized using an Odyssey Infrared Imaging System (LI-COR Biosciences, Lincoln, NE, USA).

Preparation of Sepharose $4 B$ beads and in vitro pull-down assay. CNBr-activated Sepharose 4B beads $(0.1 \mathrm{~g})$ were washed five times with $1 \mathrm{mM} \mathrm{HCl}$ and collected by centrifugation at $500 \mathrm{x}$ g for $3 \mathrm{~min}$ at $4^{\circ} \mathrm{C}$. Subsequently, the beads were incubated with $3 \mathrm{mg}$ IBC or DMSO in coupling buffer $\left[0.1 \mathrm{M} \mathrm{NaHCO}_{3}\right.$ and $\left.0.5 \mathrm{M} \mathrm{NaCl}(\mathrm{pH} 8.3)\right]$ with gentle rocking overnight at $4^{\circ} \mathrm{C}$. The beads were then washed five times with coupling buffer to remove excess ligand and incubated in blocking buffer [0.1 M Tris- $\mathrm{HCl}(\mathrm{pH} 8.0)]$ overnight at $4^{\circ} \mathrm{C}$. Afterwards, the beads were alternatively washed in three cycles with $0.1 \mathrm{M}$ acetic acid buffer ( $\mathrm{pH} 4.0$ ) containing $0.5 \mathrm{M} \mathrm{NaCl}$ and $0.1 \mathrm{M}$ Tris- $\mathrm{HCl}(\mathrm{pH} 8.0$ ) containing $0.5 \mathrm{M} \mathrm{NaCl}$, and then resuspended in $500 \mu \mathrm{l}$ PBS. IBC-Sepharose 4B beads (or only Sepharose $4 \mathrm{~B}$ as a control) were then incubated with cellular supernatant fractions of HepG2 or Hep3B cells $(500 \mu \mathrm{g})$ in reaction buffer [50 mM Tris (pH 7.5), $5 \mathrm{mM}$ EDTA, $150 \mathrm{mM}$ $\mathrm{NaCl}, 1 \mathrm{mM} \mathrm{DTT}, 0.01 \% \mathrm{NP} 40$ and $0.02 \mathrm{mM} \mathrm{PMSF}]$ containing $2 \mu \mathrm{g} / \mathrm{ml} \mathrm{BSA}$ and protease inhibitor cocktail (Roche Applied Science, Penzberg, Germany) with gentle rocking overnight at $4^{\circ} \mathrm{C}$. Finally, the beads were washed five times with reaction buffer, and the bound proteins were visualized by western blotting according to the aforementioned protocol.

Immunoprecipitation (IP) and in vitro kinase assay. The pCMV3-RSK2 expression vector was transiently introduced into HepG2 cells, and total protein was extracted using IP lysis buffer (Beyotime Institute of Biotechnology). Cell extracts $(300 \mu \mathrm{g})$ were incubated with $2 \mu \mathrm{g}$ anti-Flag tag antibody overnight at $4^{\circ} \mathrm{C}$, followed by incubation with $20 \mu \mathrm{l}$ of protein A/G agarose beads (Santa Cruz Biotechnology, Inc.) for $2 \mathrm{~h}$ at $4^{\circ} \mathrm{C}$. The precipitated beads were washed three times with lysis buffer and twice with 1X kinase buffer (Cell Signaling Technology, Inc.). The kinase reactions were performed in a total of $40 \mu \mathrm{l} 1 \mathrm{X}$ kinase buffer supplemented with $200 \mu \mathrm{M}$ ATP (Cell Signaling Technology, Inc.), $1 \mu \mathrm{g}$ recombinant human histone H3 (New England BioLabs, Inc., Ipswich, MA, USA), and 10 or $20 \mu \mathrm{M} \mathrm{IBC}$ at $30^{\circ} \mathrm{C}$ for $30 \mathrm{~min}$. Reactions were terminated with 6X SDS sample buffer (Beyotime Institute of Biotechnology), and then the supernatants were boiled for $5 \mathrm{~min}$ at $95^{\circ} \mathrm{C}$ and resolved by $15 \%$ SDS-PAGE. The phosphorylation levels of histone $\mathrm{H} 3$ were detected by western blotting according to the aforementioned protocol.

The effect of IBC on the endogenous RSK2 activity was further analyzed. HepG2 cells were starved in serum-free DMEM medium for $24 \mathrm{~h}$ at $37^{\circ} \mathrm{C}$ and treated with 10 or $20 \mu \mathrm{M}$ IBC for $2 \mathrm{~h}$ prior to exposure to EGF $(10 \mathrm{ng} / \mathrm{ml})$ for $15 \mathrm{~min}$ at $37^{\circ} \mathrm{C}$. Cell extracts $(500 \mu \mathrm{g})$ were used for IP with RSK2 antibody according to the aforementioned protocol, and then an in vitro kinase assay was performed with histone $\mathrm{H} 3$ peptide as a substrate.

Reporter gene assay. HepG2 or Hep3B cells were seeded into 24-well plates at a density of $1 \times 10^{5}$ cells/well, and then were co-transfected with AP-1 luciferase reporter vector $(1.0 \mu \mathrm{g})$ and pRL-TK Renilla luciferase vector $(0.02 \mu \mathrm{g})$ (Promega Corporation, Madison, WI, USA) using jetPEI DNA transfection reagent. At $24 \mathrm{~h}$ after transfection, cells were serum-starved for another $12 \mathrm{~h}$ and pretreated with 10 or $20 \mu \mathrm{M}$ IBC for $4 \mathrm{~h}$ at $37^{\circ} \mathrm{C}$, followed by stimulation with EGF $(10 \mathrm{ng} / \mathrm{ml})$ for $12 \mathrm{~h}$ at $37^{\circ} \mathrm{C}$. Cells were lysed with passive lysis buffer (Promega Corporation) for $20 \mathrm{~min}$ with gentle shaking, and then the firefly luciferase and Renilla luciferase activities were measured using a Dual-Luciferase assay system (Promega Corporation) in a FB12 Luminometer from Titertek-Berthold (Berthold Detection Systems GmbH, Pforzheim, Germany). The firefly luciferase activity was normalized to Renilla luciferase activity to equalize the transfection efficiency.

Statistical analysis. All data were analyzed using SPSS 16.0 and GraphPad Prism 5.0 software (GraphPad Software, Inc., La Jolla, CA, USA). Data from at least three independent experiments are expressed as the mean \pm standard deviation. An unpaired Student's t-test was employed to evaluate the difference between two groups. The differences were determined using one-way analysis of variance with Dunnett's post hoc corrections for multiple comparisons. $\mathrm{P}<0.05$ was considered to indicate a statistically significant difference.

\section{Results}

Computational modeling between IBC and ERKs/RSK2. IBC is a prenylated chalcone of the class flavonoid (Fig. 1A). The predicted docking structures of IBC into the binding pockets of ERKs and RSK2 kinases are depicted in Fig. 1B. Additionally, the ligand-protein interactions of IBC-ERKs/RSK2 complexes in two-dimensional diagrams are furtherdepicted in Fig. S1.IBC docked inside the ATP binding pocket of ERK1 (Fig. 1B-a) and formed five hydrogen-bonds with ERK1, with three involved in the backbone atoms of the residues of Asp123, Met125 and Lys72, while the other two engaged with the side-chain atoms of the residues of Lys71 and Tyr53 in close proximity to the ATP binding pocket (Fig. 1B-b and S1A). Among these five residues, Asp123 and Met125 were located in the hinge loop and Tyr53 was the gate residue in the glycine-rich loop, which also developed $\pi$-interactions with IBC between their benzene rings (Fig. 1B-b and S1A). Additionally, the 3-methyl-2-butene tail of the ligand located inside a hydrophobic pocked formed by the residues of Tyr53, Ile73, Ile89 and Ile120, while the other carbon atoms of IBC also created the hydrophobic interaction with the side-chains of the residues Ile48, Tyr53, Met55, Va156, Ala69, Ile101, Leu124, Met125 and Leu173 around the ATP binding site (Fig. S1A). The docking of this compound to ERK2 provided a similar binding pose as that between IBC and ERK1.

However, the docking of IBC to the N-terminal kinase domain (NTKD) of RSK2 provided a binding pose (Fig. 1B-c) 
A<smiles>CC(C)=CCc1c(O)ccc(C(=O)/C=C/c2ccc(O)cc2)c1O</smiles>

B
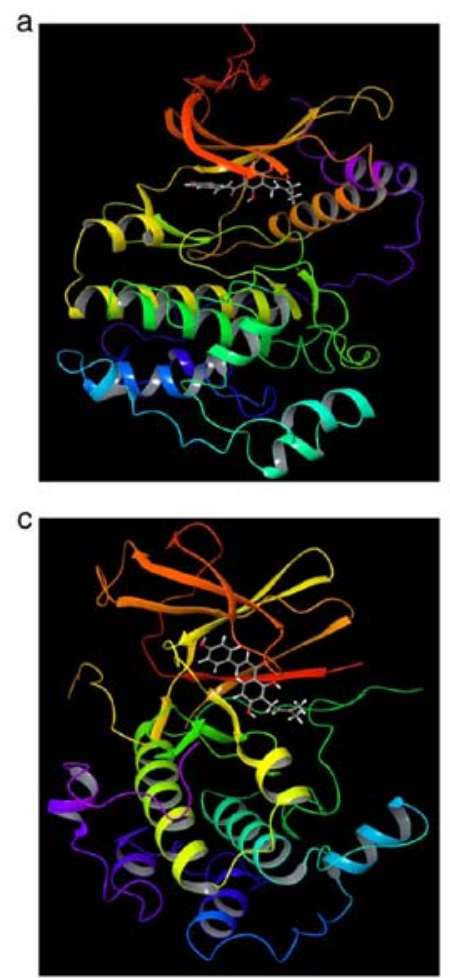
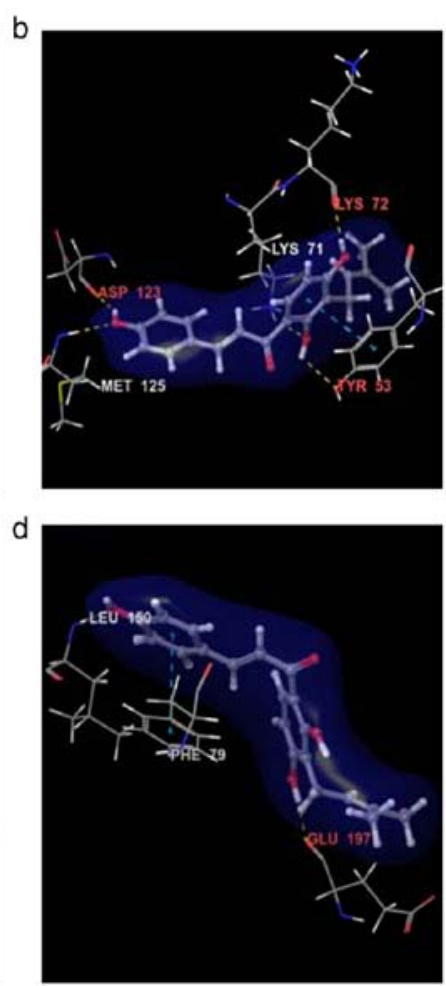

Figure 1. Predicted models of the ERKs/RSK2-IBC complexes. (A) Chemical structure of IBC. (B) Computational models of ERK1/RSK2 $2^{\mathrm{NTKD}}$-IBC complexes (B-a) The binding poses between IBC and ERK1. (B-b) Hydrogen bonds between IBC and the five residues of Asp123, Met125, Try53, Lys71 and Lys72 in the ATP binding site of ERK1. (B-c) The binding poses between IBC and RSK2 ${ }^{\text {NTKD }}$. (B-d) Hydrogen bonds between IBC and two residues of Leu50 and Glu197 in the ATP binding site of RSK2 ${ }^{\text {NTKD }}$. The figures were generated using Maestro. The $\alpha$-helices are drawn as cylinders and the $\beta$-strands as arrows. IBC is depicted as stick models and protein residues are depicted as line models. ERKs, extracellular signal-regulated kinases; RSK2, ribosomal S6 kinase 2; IBC, isobavachalcone; NTKD, N-terminal kinase domain.

similar to the SL0101/afzelin-bound form (21), which demonstrated notable structural rearrangements of the $\mathrm{N}$-lobe, compared with the AMP-PNP-bound form (33) as a typical molecular architecture of AGC kinases (34). The distinct features of the conformational changes of RSK2 ${ }^{\mathrm{NTKD}}$ from the AMP-PNP-bound form (33) were described previously (21). In the docking model of IBC-RSK2 ${ }^{\text {NTKD }}$, IBC formed two hydrogen bonds with RSK2, with one involved in the backbone amide group of the hinge loop residue Leu150, and the other engaged with the backbone carbonyl oxygen of the residue Glu197 (Fig. 1B-d). IBC also developed $\pi$-interactions between the benzene rings with the gate residue Phe79 in the glycine-rich loop (Fig. 1B-d) and Phe212 in the DFG motif of the activation loop (Fig. S1B). Additionally, the 3-methyl-2-butene tail of the ligand located inside a hydrophobic pocked formed by the residues of Ile50, Leu155, Phe212 and Leu214, while the other carbon atoms of IBC also created hydrophobic interactions with the side-chains of the residues Phe79, Val82, Ala98, Leu102, Val131, Leu145, Leu147, Phe149, Leu150, Leu155, Leu200 and Phe212 around the ATP binding site (Fig. S1B). The docking energy between this compound and RSK2 C-terminal kinase domain (CTKD) was demonstrated to be $>2.0 \mathrm{kcal} / \mathrm{mol}$ higher, compared with between IBC and RSK2 $2^{\text {NTKD }}$ from virtual screening and induced fit docking (Table SI). Thus, it was considered that this ligand could be primarily bound inside the ATP binding pocket in the N-terminal kinase domain of RSK2. Finally, these computational results indicate that IBC possibly exhibits ATP-competitive inhibitory effects on ERK1/2 and RSK2 kinases.

$I B C$ inhibits the proliferation of liver cancer cells. In view of the computer predication that IBC may be a potential inhibitor of ERKs/RSK2 signaling, the cytotoxic effects of IBC on liver cancer cells and immortalized hepatocytes were investigated. As depicted in Fig. 2A, IBC significantly decreased the viability of liver cancer HepG2 and Hep3B cells in a concentration- and time-dependent manner. The $\mathrm{IC}_{50}$ values of IBC on HepG2 and Hep3B cells at $48 \mathrm{~h}$ were 16.45 and $13.22 \mu \mathrm{M}$, respectively. In contrast, a less significant cytotoxic effect was observed in immortalized normal liver L02 cells. The EdU incorporation assay was performed to further determine the effects of IBC on the proliferation of HepG2 and Hep3B cells. As depicted in Fig. 2B, following exposure to various concentrations of IBC for $48 \mathrm{~h}$, the ratio of EdU-positive cells was gradually reduced with the increasing concentrations of IBC. Furthermore, the colony-forming ability of HepG2 and Hep3B cells was attenuated by IBC in a concentration-dependent manner (Fig. 2C). Collectively, these observations indicated that IBC effectively suppresses the viability and proliferation of liver cancer cells rather than normal hepatocytes.

$I B C$ induces cell apoptosis in liver cancer cells. The effects of IBC on cell cycle distribution and apoptosis were further analyzed using flow cytometry. Notably, it was determined that IBC exerted no notable influence on cell cycle 
A

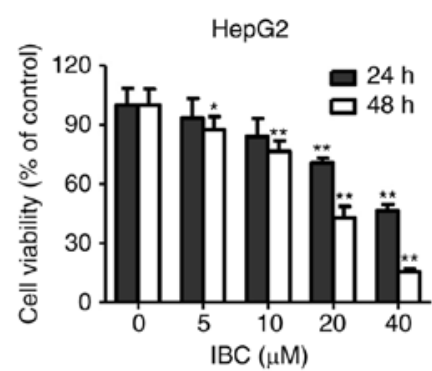

B

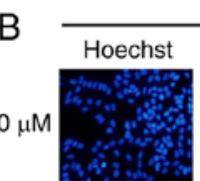

$10 \mu \mathrm{M}$

$20 \mu \mathrm{M}$

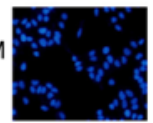

C

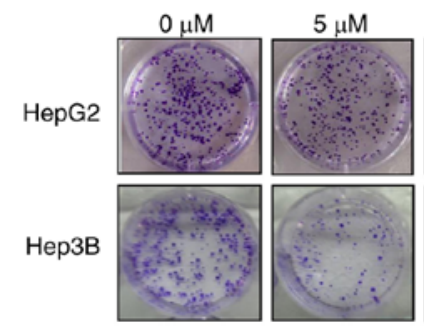

HepG2
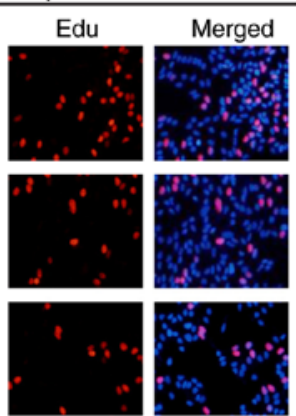
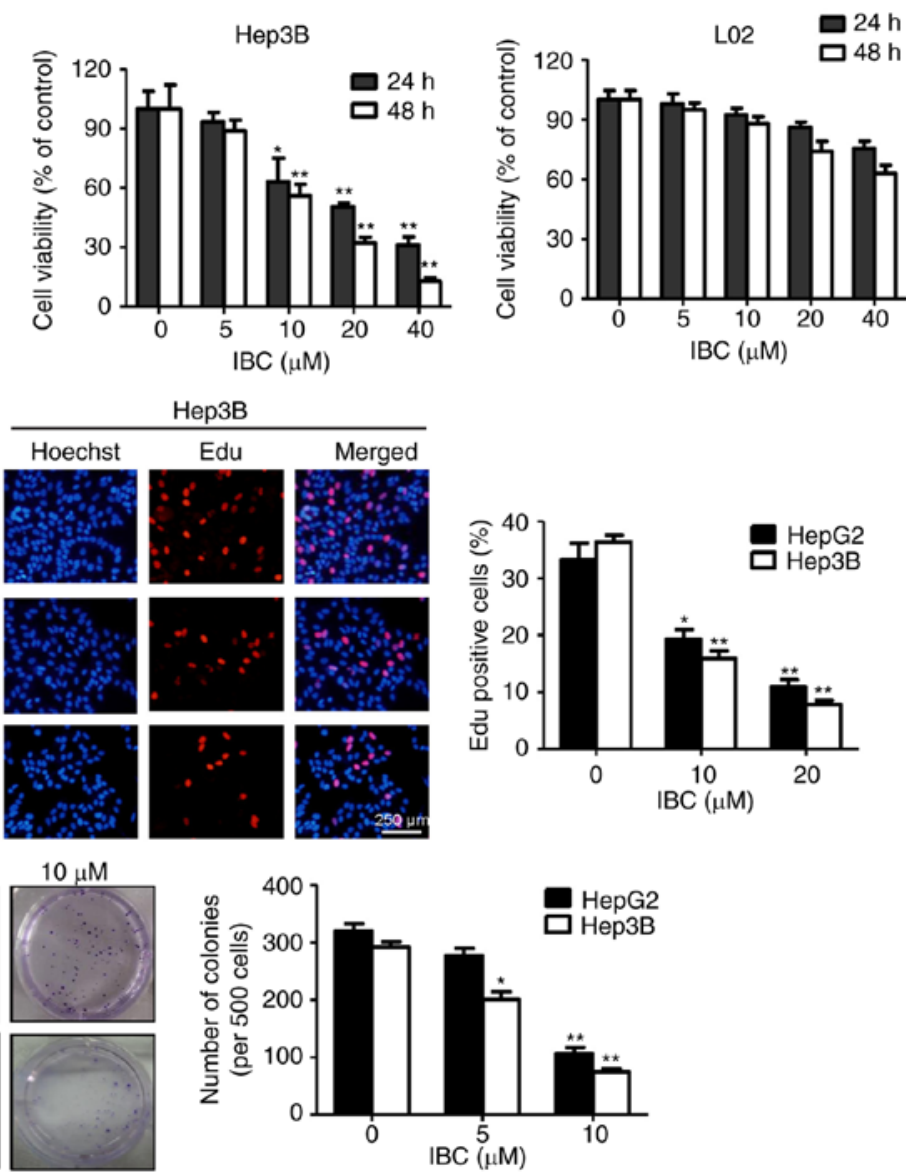

Figure 2. IBC inhibits the proliferation of liver cancer cells. (A) HepG2, Hep3B and L02 cells were treated with different concentrations of IBC for 24 or $48 \mathrm{~h}$, and cell viability was assessed by Cell Counting Kit-8 assay. (B) HepG2 or Hep3B cells were treated with different concentrations of IBC for 48 h, and cell proliferation ability was analyzed using an EdU incorporation assay. EdU-labeled proliferative cells (red) and Hoechst-stained nuclei (blue) were observed under a fluorescence microscope (magnification, x200). (C) HepG2 or Hep3B cells were incubated with different concentrations of IBC for 2 weeks, and then cell growth was detected with a colony formation assay. All data were expressed as the mean \pm standard deviation ( $\mathrm{n}=3$ ). ${ }^{*} \mathrm{P}<0.05$ and ${ }^{* * *} \mathrm{P}<0.005$ vs. vehicle-treated control. IBC, isobavachalcone.

distributions of HepG2 and Hep3B cells, even up to the concentration of $20 \mu \mathrm{M}$ (Fig. S2). However, treatment with IBC could induce a notable concentration-dependent increase of cell apoptosis, particularly early apoptosis, in HepG2 and Hep3B cells (Fig. 3A). Subsequently, the effect of IBC on apoptosis-associated molecules was investigated. As depicted in Fig. 3B, exposure of HepG2 cells to IBC caused the downregulation of MDM2 and $\mathrm{Bcl}-2$, along with the increase of $\mathrm{p} 53$ and Bax, in a concentration-dependent manner. Additionally, procaspase- 9 exhibited a significant decrease response to IBC treatment, concomitant with the increasing levels of caspase-3 and -7 activities and cleavage of PARP (Fig. 3C), indicating a hierarchical activation of the apoptotic caspase cascade. Collectively, these results indicated that the induction of caspase-mediated apoptosis was involved in the antitumor activity of IBC on liver cancer cells.

IBC directly binds with ERKS/RSK2 and inhibits RSK2 kinase activity. It has been determined from computer-aided virtual screening and molecular modeling that ERK1/2 and RSK2 may represent potential targets of IBC. To further determine whether IBC directly binds with ERK1/2 and RSK2, an in vitro pull-down assay using HepG2 or Hep3B cell lysates was conducted. As depicted in Fig. 4A, ERK1/2 and RSK2 could bind to the IBC-Sepharose 4B beads, but not to DMSO-Sepharose 4B beads. Additionally, IBC could not selectively bind to JNK/SAPK (Fig. 4A).

Subsequently, an IP kinase assay was conducted to investigate the effect of IBC on RSK2 kinase activity. Histone H3 is a well-known phosphorylation substrate of RSK2 (35). The full-length RSK2 was transfected into HepG2 cells and RSK2 protein was immunoprecipitated by Flag-tagged antibody. The precipitates were subjected to an in vitro kinase assay with various concentrations of IBC and histone $\mathrm{H} 3$ peptide as a substrate. As depicted in Fig. 4B, treatment with IBC inhibited the levels of histone $\mathrm{H} 3$ phosphorylation at Ser10 in a concentration-dependent manner, compared with untreated control, indicating that IBC could effectively block RSK2 kinase activity in vitro. Additionally, whether IBC interferes with the activity of endogenous RSK2 in HepG2 cells was investigated. Cells were treated with various concentrations of IBC for $2 \mathrm{~h}$, followed by stimulation with EGF. The results from RSK2 IP kinase assay revealed that IBC also significantly inhibited EGF-induced endogenous RSK2 kinase activity (Fig. 4C). Overall, these observations indicated that IBC could effectively suppress the RSK2 activity by directly binding to ERK1/2 and RSK 2 in liver cancer cells. 

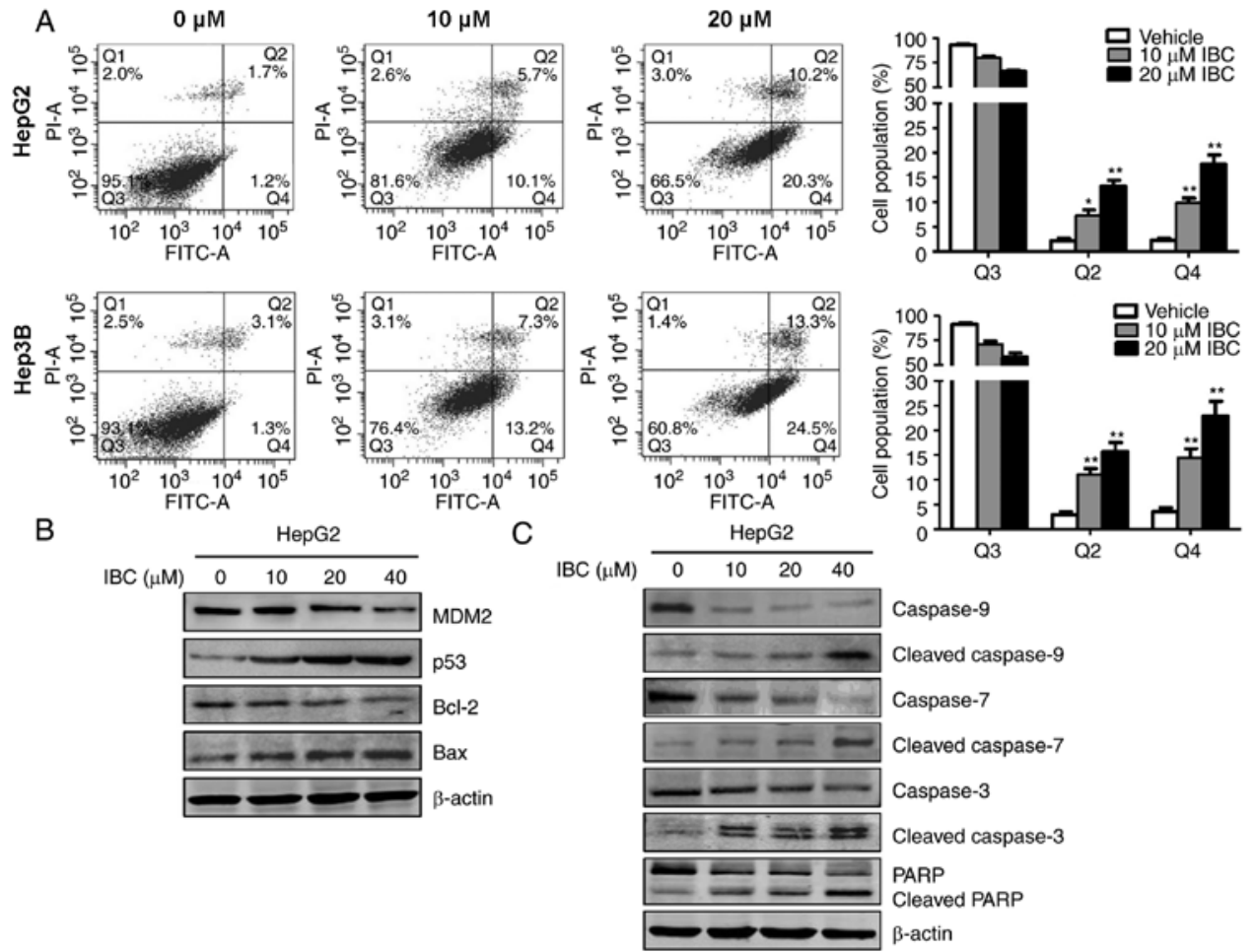

Figure 3. IBC induces cell apoptosis in liver cancer cells. (A) HepG2 or Hep3B cells were treated with different concentrations of IBC for $48 \mathrm{~h}$, and apoptosis was analyzed using flow cytometry with Annexin V/PI double staining assay. Cells were categorized into viable cells (Q3), early apoptotic cells (Q4), late apoptotic cells (Q2) and dead cells (Q1). (B) HepG2 cells were treated with different concentrations of IBC for $48 \mathrm{~h}$. Cell lysates were harvested and immunoblotted with anti-MDM2, p53, Bcl-2 and Bax antibodies. (C) Cells were treated with different concentrations of IBC for $48 \mathrm{~h}$, and then were subjected to immunoblotting analysis with caspase-9, caspase-7, caspase- 3 and PARP. $\beta$-actin was used as the loading control. Data are presented as the mean \pm standard deviation ( $\mathrm{n}=3$ ). " $\mathrm{P}<0.05$ and $^{* *} \mathrm{P}<0.005$ vs. vehicle-treated control. IBC, isobavachalcone; PI, propidium iodide; FITC, fluorescein isothiocyanate; MDM2, mouse double minute 2 homolog; Bcl-2, B-cell lymphoma 2; Bax, Bcl-2-associated X; PARP, poly ADP-ribose polymerase.

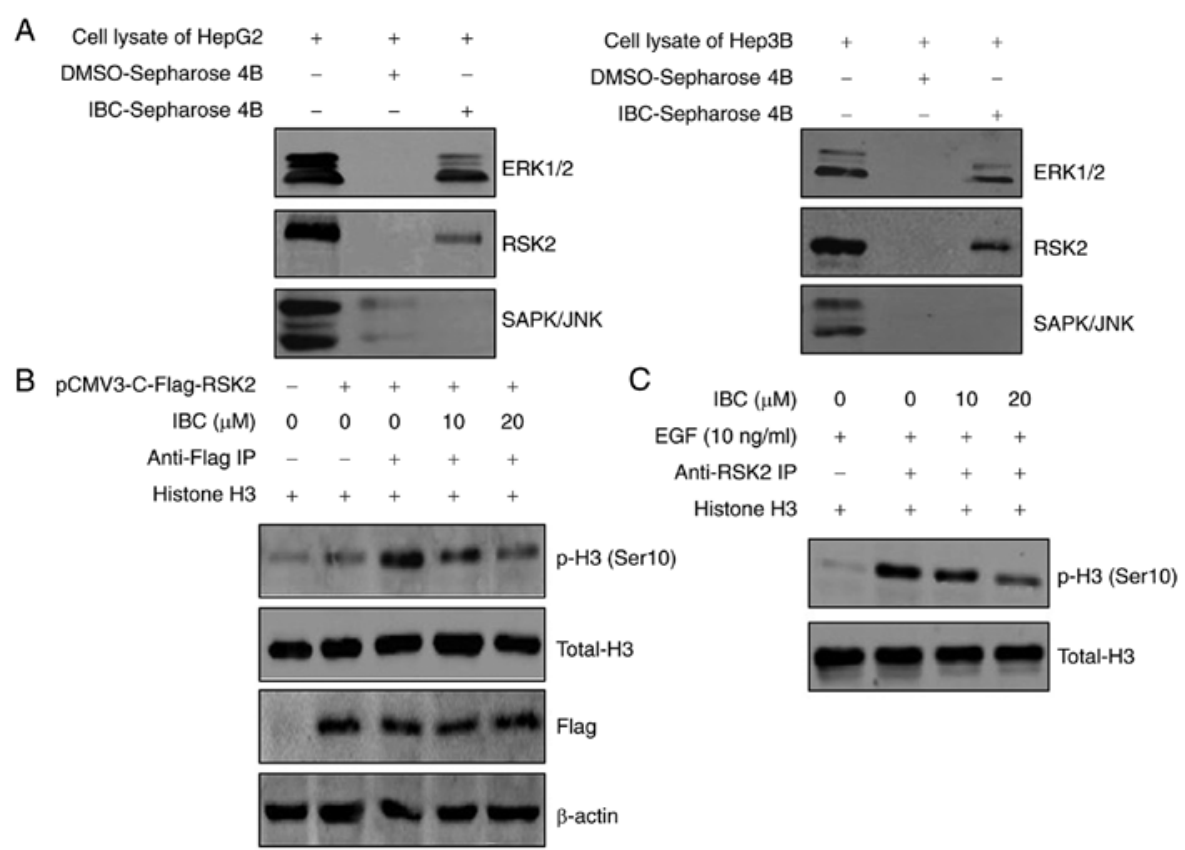

Figure 4. IBC directly binds with ERK1/2 and RSK2, and inhibits RSK2 kinase activity. (A) For the in vitro IBC pull-down assay, lane 1 depicts cell lysates from HepG2 or Hep3B cells used as input controls, lane 2 depicts cell lysates incubated with DMSO-Sepharose4B beads used as the negative controls and lane 3 depicts cell lysates incubated with IBC-Sepharose4B beads, and then the precipitated proteins were visualized by western blotting using antibodies against ERK1/2, RSK2 and SAPK/JNK. (B) HepG2 cells were transfected with pCMV3-RSK2 or control vector, and then cell lysates were immunoprecipitated with Flag-tagged antibody. The kinase assay was performed using different concentrations of IBC and histone H3 peptide as a substrate. The expression levels of p-histone H3 (Ser10), histone H3 and Flag-tag were detected by western blotting. (C) HepG2 cells were serum-starved for $24 \mathrm{~h}$, treated with different concentrations of IBC for $2 \mathrm{~h}$ and then stimulated with EGF $(10 \mathrm{ng} / \mathrm{ml})$ for $15 \mathrm{~min}$. Cell lysates were immunoprecipitated with RSK2 antibody, and then RSK2 kinase activity was determined using an in vitro kinase assay with histone $\mathrm{H} 3$ peptide as a substrate. IBC, isobavachalcone; ERK1/2, extracellular signal-regulated kinase 1/2; RSK2, ribosomal S6 kinase 2; DMSO, dimethyl sulfoxide; SAPK/JNK, stress-activated protein kinase/c-Jun NH2-terminal kinase; IP, immunoprecipitation; EGF, epidermal growth factor; p-, phospho-. 
A

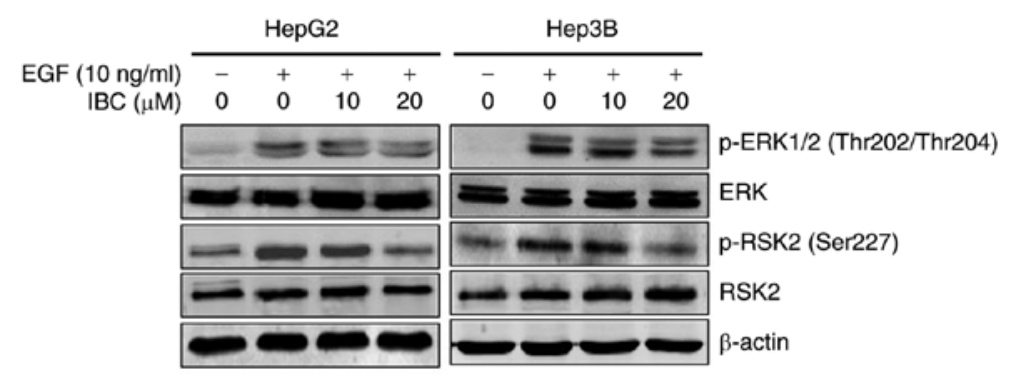

B

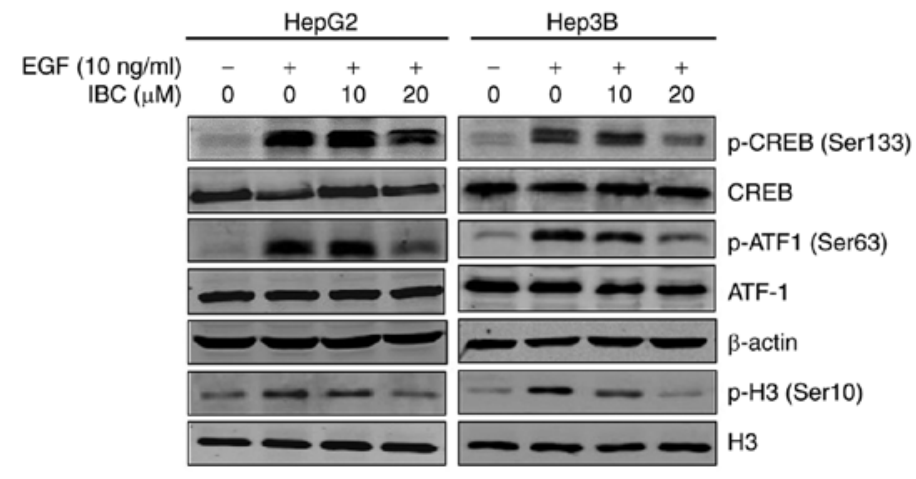

C
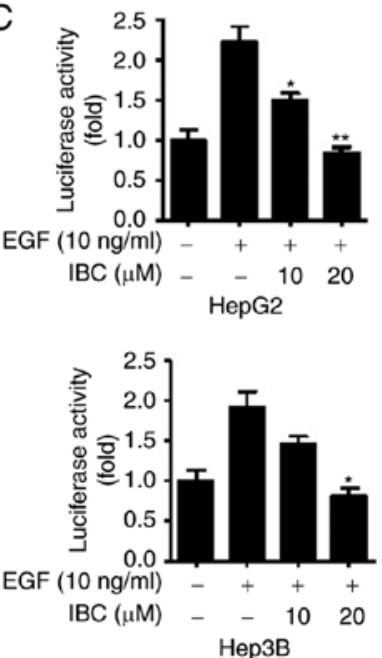

Figure 5. IBC suppresses EGF-induced activation of the ERKs/RSK2 signaling pathway in liver cancer cells. (A) HepG2 or Hep3B cells were serum-starved for $24 \mathrm{~h}$, and then treated with various concentrations of IBC for $2 \mathrm{~h}$ followed by exposure to EGF $(10 \mathrm{ng} / \mathrm{ml})$ for 15 min. Cell lysates were harvested for immunoblotting with anti-ERK1/2, p-ERK1/2 (Thr202/Thr204), RSK2 and p-RSK2 (Ser227) antibodies. (B) HepG2 or Hep3B cells were serum starved for $24 \mathrm{~h}$, and then treated with various concentrations of IBC for $2 \mathrm{~h}$ followed by stimulation with EGF. The expression levels of CREB, p-CREB (Ser133), ATF1, p-ATF1 (Ser63) and p-histone H3 (Ser10) were detected by western blotting. $\beta$-actin and histone H3 were used as loading controls. (C) HepG2 or Hep3B cells were co-transfected with AP-1 luciferase reporter gene and pRL-TK Renilla luciferase vector. At $24 \mathrm{~h}$ after transfection, cells were serum-starved for $12 \mathrm{~h}$, and then treated with various concentrations of IBC for $4 \mathrm{~h}$ followed by exposure to EGF for $12 \mathrm{~h}$. The firefly luciferase activity was determined in cell lysates and normalized against Renilla luciferase activity. Data are presented as the mean \pm standard deviation ( $\mathrm{n}=3$ ). ${ }^{*} \mathrm{P}<0.05$ and ${ }^{* *} \mathrm{P}<0.01$ vs. vehicle-treated control stimulated by EGF. IBC, isobavachalcone; EGF, epidermal growth factor; ERKs, extracellular signal-regulated kinases; RSK2, ribosomal S6 kinase 2; CREB, cAMP response element-binding protein; ATF1, activating transcription factor 1; AP-1, activator protein 1; p-, phospho-.

IBC suppresses EGF-induced activation of the ERKs/RSK2 signaling pathway. Based on the aforementioned experimental results, it was concluded that IBC exerted antitumor activity on liver cancer cells through regulating the ERKs/RSK2 signaling pathway. The effects of IBC on EGF-induced phosphorylation of ERK1/2 and RSK2 were examined by western blotting. As expected, EGF, a tumor promoter, induced the phosphorylation of ERK1/2 and RSK2 in HepG2 and Hep3B cells (Fig. 5A). Treatment with IBC significantly inhibited EGF-induced phosphorylation of RSK2 in a concentration-dependent manner (Fig. 5A), consistent with the decrease of endogenous RSK2 activity by IBC. However, the EGF-induced phosphorylation of ERK1/2 does not appear to be affected by IBC (Fig. 5A). To demonstrate the inhibitory role of IBC on the ERKs/RSK2 signaling pathway, the status of its downstream target proteins, including CREB, ATF1 and histone $\mathrm{H} 3$, whose phosphorylation is increased in response to EGF-induced ERKs/RSK2 activation, were evaluated. As depicted in Fig. 5B, the phosphorylation levels of CREB, ATF1 and histone H3 induced by EGF were notably abrogated by IBC in a concentration-dependent manner. AP- 1 is a dimeric transcription factor composed of Jun, Fos or ATF protein family members (36). It is well known that RSK2 is involved in the regulation of AP-1 transcriptional activity through its phosphorylation of histone $\mathrm{H} 3$ at Ser10 (31). The present results indicated that EGF promoted AP-1 transcriptional activity and that treatment with IBC resulted in a concentration-dependent inhibition of AP-1 transactivation in liver cancer cells (Fig. 5C). Collectively, these results provided evidence that IBC could effectively block the ERKs/RSK2 downstream signaling pathway, which may be responsible for the anti-proliferation activity of IBC to some extent.

RSK2-mediated signaling is involved in IBC-induced suppression of liver cancer cells. To further determine the role of RSK2 in IBC-induced suppression of liver cancer cells, the expression levels of RSK2 in HepG2, Hep3B and L02 cells were detected. As depicted in Fig. 6A, compared with L02 cells, elevated total- and phospho-RSK2 protein levels were observed in HepG2 and Hep3B cells. On this basis, a vector encoding RSK2 was transfected into L02 cells, and then cell viability was evaluated with a CCK- 8 assay under the conditions with or without IBC. Expectedly, overexpression of RSK2 significantly promoted the proliferation of L02 cells (Fig. S3). Furthermore, enforced RSK2 expression in L02 cells notably enhanced the inhibitory effect of IBC on cell 
A

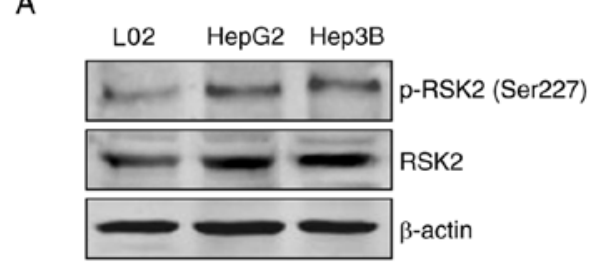

C

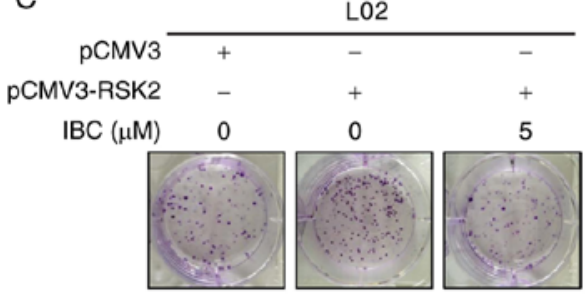

B
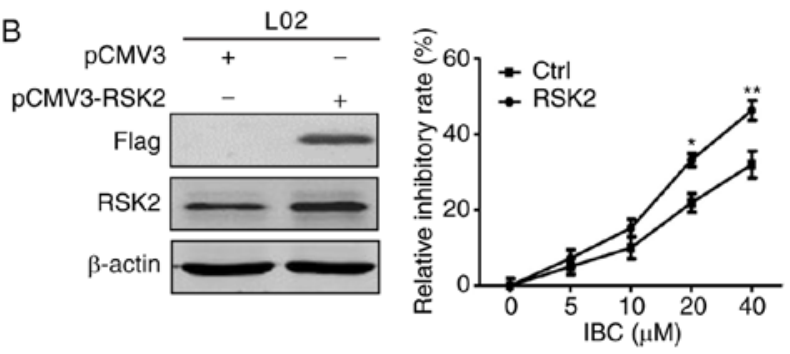
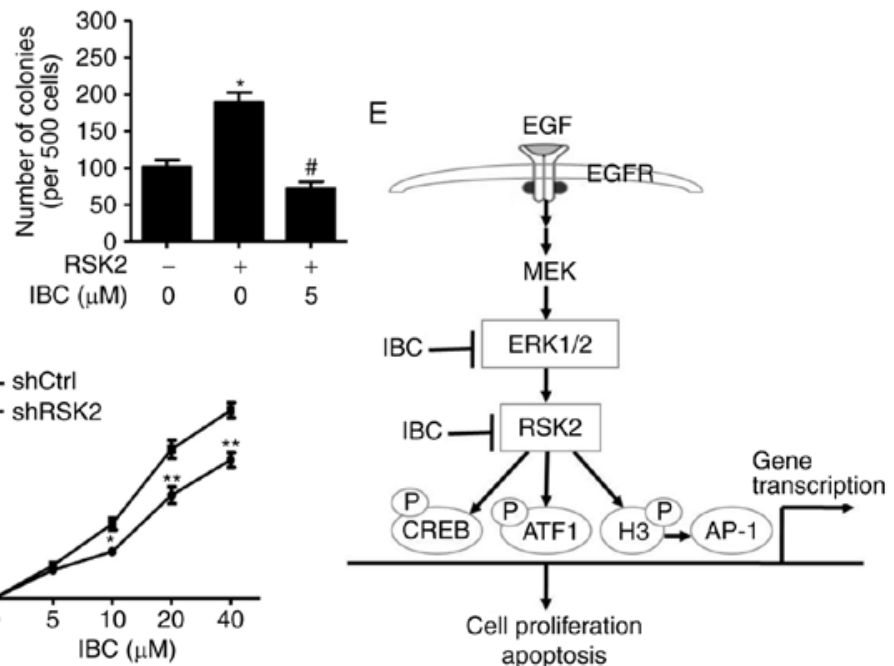

Figure 6. IBC blocks RSK2-mediated cell proliferation in liver cancer cells. (A) Cell lysates from L02, HepG2 or Hep3B cells were harvested and analyzed by immunoblotting with anti-RSK2 or p-RSK2 (Ser227). $\beta$-actin was used as the loading control. (B) L02 cells were transfected with pCMV3-RSK2 or pCMV3 control vector. After being transfected for $24 \mathrm{~h}$, cells were aliquoted into 96 -well plates and incubated with different concentrations of IBC for another $48 \mathrm{~h}$. Cell viability was assessed with a CCK-8 assay. (C) L02 cells transfected with pCMV3-RSK2 or control vector were treated with indicated concentrations of IBC for 2 weeks, and then cell growth was detected with a colony formation assay. (D) HepG2 cells were transfected with shRSK2 or shCtrl control vector. After being transfected for $24 \mathrm{~h}$, cells were aliquoted into 96-well plates and incubated with different concentrations of IBC for another $48 \mathrm{~h}$. Cell viability was assessed with a CCK- 8 assay. Data are expressed as the mean \pm standard deviation $(\mathrm{n}=3)$. " $\mathrm{P}<0.05$ and ${ }^{* *} \mathrm{P}<0.01$ vs. cells transfected with control vector, ${ }^{\#} \mathrm{P}<0.005$ vs. vehicle-treated cells transfected with RSK2. (E) Proposed signal transduction pathways modulated by IBC in liver cancer cells. IBC suppressed cell proliferation and induced cell apoptosis by directly targeting ERK1/2 and RSK2, thereby blocking the activation of its downstream transcription factors, including CREB, ATF1, histone H3 and AP-1. IBC, isobavachalcone; RSK2, ribosomal S6 kinase 2; CCK-8, Cell Counting Kit-8; Ctrl, control; sh, short hairpin; EGF, epidermal growth factor; EGFR, epidermal growth factor receptor; MEK, mitogen-activated protein kinase kinase; ERK1/2, extracellular signal-regulated kinase 1/2; CREB, cAMP response element-binding protein; ATF1, activating transcription factor 1; AP-1, activator protein 1; $\mathrm{P}$, phosphorylation.

viability (Fig. 6B). Additionally, it was observed that RSK2 overexpression notably increased colony formation capacity in L02 cells, whereas IBC effectively counteracted the effect of RSK2 on inducing colony formation (Fig. 6C). Conversely, RSK2 knockdown in HepG2 cells reduced the effect of IBC on suppressing cell proliferation in a concentration-dependent manner, compared with the control cells (Fig. 6D). Overall, these results supported the assertion that the RSK2-mediated signaling pathway serves a critical role in the inhibitory effect of IBC on liver cancer cells.

\section{Discussion}

Deregulation of Raf/MEK/ERKs signaling is implicated in cell proliferation, survival, metastasis and tumorigenesis, along with the overwhelming frequency in which this pathway is aberrantly activated in human cancer types, including melanomas, colorectal cancer, non-small cell lung cancer and liver cancer (8). RSK2 is a downstream kinase of ERKs and, functionally speaking, is located between ERKs and its own target transcription factors. RSK2 was reportedly involved in the proliferation of various cancer cells and neoplastic cell transformation induced by tumor promoters, including EGF and 12-O-tetradecanoylphorb ol-13-acetate $(31,37)$. Mice lacking RSK2 exhibited the reduced c-Fos-dependent osteosarcoma formation (38). Inhibition of RSK2 significantly blocked the proliferation and invasion of human glioblastoma cells and enhanced the effectiveness of temozolomide and irradiation therapy in temozolomide-resistant glioblastoma cells (39). Notably, increased total and activated RSK2 protein levels are exhibited in various cancer cell lines and solid cancer types, including melanoma, glioblastoma, and multiple myeloma, and are correlated with advanced tumor stage and poor survival prognosis of patients (39-41). The mRNA expression of RSK2 was significantly increased in HCC tissues, compared with adjacent non-tumor liver tissues according to the analysis of microarray gene expression data (42). It was also observed that the levels of total and phosphorylated RSK2 were elevated in HepG2 and Hep3B cells, compared with normal liver L02 cells. Enforced expression of RSK2 in L02 cells substantially promoted cell proliferation and colony formation. These observations indicated that RSK2 serves a key role in cell proliferation, transformation and cancer development and that targeting RSK2 may represent a potential therapeutic strategy for numerous human cancer types, including liver cancer. 
RSK2 is composed of two functional kinase domains that are activated by a series of phosphorylations in a sequential manner (10). The NTKD of RSK2 serves a key role in the transducing RSK2 activation signal to its substrates (10). However, the activation of CTKD by upstream ERK1/2 is required for the initiation of the activation process, resulting in activation of RSK2 NTKD (10). Therefore, high-throughout virtual screening was performed to identify the potential inhibitors targeting ERKs/RSK2 from $>500$ traditional Chinese medicine compounds. The results demonstrated that IBC, a chalcone constituent from Psoralea corylifolia and Angelica keiskei (43), could bind to the ATP binding pocket of ERK1/2, as well as NTKD of RSK2, indicating that IBC may be an ATP-competitive inhibitor targeting ERK1/2 and RSK2. An in vitro pull-down assay further demonstrated that IBC directly bound with ERK1/2 and RSK2. Furthermore, IBC was demonstrated not only to suppress RSK2 kinase activity, but also to abate EGF-induced phosphorylation of RSK2. The decrease in ERK1/2 activity caused by IBC may account for the abrogation of RSK2 phosphorylation. Notably, it was observed that IBC did not modulate the phosphorylation of ERK1/2. Binding with IBC may abrogate the catalytic activity of ERK1/2 on its downstream substrates or directly interfere the interaction between ERK1/2 and its substrates, but does not appear to affect the phosphorylation of ERK1/2 mediated by its upstream kinases. Collectively, these results demonstrated that ERK1/2 and RSK2 are potential targets of IBC.

Among numerous biologically active chalcones, IBC is one of the most resourceful compounds and is present in a variety of plant families and species, particularly Fabaceae and Moraceae (43). It is well-known that IBC possesses a wide range of pharmacological effects, including anti-inflammatory, antifungal, antimicrobial, antioxidant and other activities (43). Previously, IBC has been demonstrated to exert antitumor activity against a number of cancer types. IBC exhibited notable inhibitory effects on mouse skin tumor promotion in in vivo two-stage skin carcinogenesis (44). IBC could induce apoptosis in neuroblastoma cells with no significant cytotoxicity against normal cerebellar granule cells (45). IBC was demonstrated to induce more growth limitations and apoptosis for cancer cells with elevated Akt activation rather than umbilical vein endothelial cells (HUVEC) and normal hepatocyte L02 cells (46). In the present study, it was observed that IBC could notably suppress the proliferation of HepG2 and Hep3B cells, while it has minimal effect on L02 cells, further indicating that IBC may be applicable as an efficacious and safe anticancer agent candidate. Flow cytometric analysis further revealed that IBC dose-dependently promoted the apoptosis of liver cancer cells, whereas no notable alteration was observed in cell cycle distributions following treatment with the same dose of IBC. Furthermore, the expression of apoptotic markers, including active caspase- $-3,-7$ and -9 , and cleaved PARP, was also detected in the IBC-treated liver cancer cells. These observations revealed that the antitumor activity of IBC may be associated with caspase-mediated cell apoptosis in liver cancer cells.

RSK2 inhibition was indicated to be involved in IBC-induced apoptosis. Exposure of cells to IBC caused the downregulation of MDM2, concomitant with an increase of $\mathrm{p} 53$, which may be associated with the inhibition of the
RSK2/Akt pathway by IBC, resulting in a decrease of MDM2 phosphorylation and stability $(47,48)$. The $\mathrm{p} 53$ protein is also an important substrate of RSK2, and the RSK2-p53-histone H3 complex may contribute to chromatin remodeling and cell cycle regulation, but is not required for cell apoptosis (49). Additionally, RSK2-mediated phosphorylation and inactivation of Bcl-2-associated agonist of cell death and death-associated protein kinase exerted an anti-apoptosis effect via the modulation of $\mathrm{Bcl}-2 / \mathrm{Bax}(50,51)$. The downregulation of $\mathrm{Bcl}-2$ by IBC is expected to reduce the drug resistance in liver cancer cells $(52,53)$. The possibility will be further investigated in the future. Overall, these data implied the association between RSK2 inhibition and the pro-apoptotic effect of IBC.

Various physiological and pathological functions of RSK2 are attributed to its extensive substrate specificity $(10,37)$. When activated, RSK2 is translocated to the nucleus and phosphorylates a number of diverse substrates that regulate cell proliferation, transformation, cell cycle and apoptosis, depending on the specific situation (10,37). The CREB/ATF family of transcription factors are notable substrates of RSK2, and the RSK2-CREB/ATF pathway modulates transcriptional activation of numerous target genes, including the proto-oncogenes $c$-Fos and $c$-Jun, the cell cycle genes Cyclin D and Cyclin $A$, and the anti-apoptotic gene $B c l-2(10,37)$. RSK2 mediates EGF-induced phosphorylation of histone H3 at Ser10 and promotes the expression of c-Fos and c-Jun, as well as AP-1 transactivation (31). In the present study, IBC was demonstrated to effectively inhibit EGF-induced phosphorylation of CREB, ATF1 and histone H3, along with AP-1 transactivation activity, which was responsible for the antitumor effect of IBC on liver cancer cells. The functional association between IBC and RSK2 was further demonstrated by in vitro functional experiments. Enforced RSK2 expression in L02 cells could significantly increase the selectivity of IBC to suppress cell viability of normal hepatocytes. Furthermore, RSK2 overexpression promoted cell proliferation and colony formation, which could be notably counteracted by IBC. On the contrary, silencing of RSK2 expression in HepG2 cells could decrease the inhibitory efficacy of IBC on cell proliferation. Collectively, these results demonstrated that IBC exerted antitumor activity against liver cancer cells through regulating the ERKs/RSK2 signaling pathway.

In conclusion, to the best of our knowledge, the present study demonstrated for the first time that IBC is a potential inhibitor targeting ERK1/2 and RSK2 and that inhibition of the ERKs/RSK2 signaling pathway serves a pivotal role in the anti-proliferative and pro-apoptotic effects of IBC on liver cancer cells (Fig. 6E). Therefore, IBC may represent a promising therapeutic candidate for human cancer cases with elevated ERKs/RSK2 activity.

\section{Acknowledgements}

Not applicable.

\section{Funding}

The present study was supported by the National Natural Science Foundation of China (grant nos. 81502411, 31770774 and 81372137) and the National Undergraduate Training 
Program for Innovation and Entrepreneurship (grant no. 201810571007).

\section{Availability of data and materials}

The datasets used and/or analyzed during the current study are available from the corresponding author on reasonable request.

\section{Authors' contributions}

$\mathrm{BL}, \mathrm{ZHu}$ and $\mathrm{ZHe}$ contributed to the conception and design of the study. BL, NX, ZW, HL, WC and XC performed the experiments and analyzed data. $\mathrm{ZHu}$ and $\mathrm{LM}$ performed bioinformatic analysis. $\mathrm{BL}, \mathrm{ZHu}$ and $\mathrm{ZHe}$ contributed to drafting and revising the manuscript. All authors read and approved the manuscript and agree to be accountable for all aspects of the research in ensuring that the accuracy or integrity of any part of the work are appropriately investigated and resolved.

\section{Ethics approval and consent to participate}

Not applicable.

\section{Patient consent for publication}

Not applicable.

\section{Competing interests}

The authors declare that they have no competing interests.

\section{References}

1. Bray F, Ferlay J, Soerjomataram I, Siegel RL, Torre LA and Jemal A: Global cancer statistics 2018: GLOBOCAN estimates of incidence and mortality worldwide for 36 cancers in 185 countries. CA Cancer J Clin 68: 394-424, 2018.

2. Kumar M, Zhao X and Wang XW: Molecular carcinogenesis of hepatocellular carcinoma and intrahepatic cholangiocarcinoma: One step closer to personalized medicine? Cell Biosci 1: 5, 2011.

3. Santarpia L, Lippman SM and El-Naggar AK: Targeting the MAPK-RAS-RAF signaling pathway in cancer therapy. Expert Opin Ther Targets 16: 103-119, 2012.

4. Yip-Schneider MT, Klein PJ, Wentz SC, Zeni A, Menze A and Schmidt CM: Resistance to mitogen-activated protein kinase kinase (MEK) inhibitors correlates with up-regulation of the MEK/extracellular signal-regulated kinase pathway in hepatocellular carcinoma cells. J Pharmacol Exp Ther 329: 1063-1070, 2009.

5. Yang $\mathrm{S}$ and Liu G: Targeting the Ras/Raf/MEK/ERK pathway in hepatocellular carcinoma. Oncol Lett 13: 1041-1047, 2017.

6. Hsu CH, Shen YC, Shao YY, Hsu C and Cheng AL: Sorafenib in advanced hepatocellular carcinoma: Current status and future perspectives. J Hepatocell Carcinoma 1: 85-99, 2014.

7. Lim HY, Heo J, Choi HJ, Lin CY, Yoon JH, Hsu C, Rau KM, Poon RT, Yeo W, Park JW, et al: A phase II study of the efficacy and safety of the combination therapy of the MEK inhibitor refametinib (BAY 86-9766) plus sorafenib for Asian patients with unresectable hepatocellular carcinoma. Clin Cancer Res 20 5976-5985, 2014

8. Roberts PJ and Der CJ: Targeting the Raf-MEK-ERK mitogen-activated protein kinase cascade for the treatment of cancer. Oncogene 26: 3291-3310, 2007.

9. Wang H, Xu L, Zhu X, Wang P, Chi H and Meng Z: Activation of phosphatidylinositol 3-kinase/Akt signaling mediates sorafenib-induced invasion and metastasis in hepatocellular carcinoma. Oncol Rep 32: 1465-1472, 2014.

10. Romeo Y, Zhang X and Roux PP: Regulation and function of the RSK family of protein kinases. Biochem J 441: 553-569, 2012.
11. Ito Y, Sasaki Y, Horimoto M, Wada S, Tanaka Y, Kasahara A, Ueki T, Hirano T, Yamamoto H, Fujimoto J, et al: Activation of mitogen-activated protein kinases/extracellular signal-regulated kinases in human hepatocellular carcinoma. Hepatology 27: 951-958, 1998.

12. Tsuboi Y, Ichida T, Sugitani S, Genda T, Inayoshi J, Takamura M, Matsuda Y, Nomoto M and Aoyagi Y: Overexpression of extracellular signal-regulated protein kinase and its correlation with proliferation in human hepatocellular carcinoma. Liver Int 24 : 432-436, 2004.

13. Bessard A, Frémin C, Ezan F, Fautrel A, Gailhouste L and Baffet G: RNAi-mediated ERK2 knockdown inhibits growth of tumor cells in vitro and in vivo. Oncogene 27: 5315-5325, 2008.

14. Xie YX, Liao R, Pan L and Du CY: ERK pathway activation contributes to the tumor-promoting effects of hepatic stellate cells in hepatocellular carcinoma. Immunol Lett 188: 116-123, 2017.

15. Liao B, Zhou H, Liang $\mathrm{H}$ and Li C: Regulation of ERK and AKT pathways by hepatitis B virus X protein via the Notch1 pathway in hepatocellular carcinoma. Int J Oncol 51: 1449-1459, 2017.

16. Schmitz KJ, Wohlschlaeger J, Lang H, Sotiropoulos GC, Malago M, Steveling K, Reis H, Cicinnati VR, Schmid KW and Baba HA: Activation of the ERK and AKT signalling pathway predicts poor prognosis in hepatocellular carcinoma and ERK activation in cancer tissue is associated with hepatitis $\mathrm{C}$ virus infection. J Hepatol 48: 83-90, 2008.

17. Kim HS, Kim SJ, Bae J, Wang Y, Park SY, Min YS, Je HD and Sohn UD: The p90rsk-mediated signaling of ethanol-induced cell proliferation in HepG2 cell line. Korean J Physiol Pharmacol 20: 595-603, 2016.

18. Yuan R, Hou Y, Sun W, Yu J, Liu X, Niu Y, Lu JJ and Chen X: Natural products to prevent drug resistance in cancer chemotherapy: A review. Ann N Y Acad Sci 1401: 19-27, 2017.

19. Raghavendra NM, Pingili D, Kadasi S, Mettu A and Prasad S: Dual or multi-targeting inhibitors: The next generation anticancer agents. Eur J Med Chem 143: 1277-1300, 2018.

20. Leelananda SP and Lindert S: Computational methods in drug discovery. Beilstein J Org Chem 12: 2694-2718, 2016.

21. Utepbergenov D, Derewenda U, Olekhnovich N, Szukalska G, Banerjee B, Hilinski MK, Lannigan DA, Stukenberg PT and Derewenda ZS: Insights into the inhibition of the p90 ribosomal S6 kinase (RSK) by the flavonol glycoside SL0101 from the $1.5 \AA$ crystal structure of the N-terminal domain of RSK2 with bound inhibitor. Biochemistry 51: 6499-6510, 2012.

22. Serafimova IM, Pufall MA, Krishnan S, Duda K, Cohen MS, Maglathlin RL, McFarland JM, Miller RM, Frödin M and Taunton J: Reversible targeting of noncatalytic cysteines with chemically tuned electrophiles. Nat Chem Biol 8: 471-476, 2012.

23. Chaikuad A, Tacconi EM, Zimmer J, Liang Y, Gray NS, Tarsounas $\mathrm{M}$ and Knapp S: A unique inhibitor binding site in ERK $1 / 2$ is associated with slow binding kinetics. Nat Chem Biol 10: 853-860, 2014.

24. Schrödinger Release 2015-2: Schrödinger Suite 2015-2 Protein Preparation Wizard; Epik version 3.2, Schrödinger, LLC, New York, NY, 2015; Impact version 6.7, Schrödinger, LLC, New York, NY, 2015; Prime version 4.0, Schrödinger, LLC, New York, NY, 2015.

25. Small-Molecule Drug Discovery Suite 2015-2: Glide, version 6.7, Schrödinger, LLC, New York, NY, 2015.

26. Schrödinger Release 2015-2: LigPrep, version 3.4, Schrödinger, LLC, New York, NY, 2015.

27. Small-Molecule Drug Discovery Suite 2015-2: Glide, version 6.7, Schrrödinger, LLC, New York, NY, 2015.

28. Friesner RA, Murphy RB, Repasky MP, Frye LL, Greenwood JR, Halgren TA, Sanschagrin PC and Mainz DT: Extra precision glide: Docking and scoring incorporating a model of hydrophobic enclosure for protein-ligand complexes. J Med Chem 49: 6177-6196, 2006.

29. Small-Molecule Drug Discovery Suite 2015-2: Schrödinger Suite 2015-2 Induced Fit Docking protocol; Glide version 6.7, Schrödinger, LLC, New York, NY, 2015; Prime version 4.0, Schrödinger, LLC, New York, NY, 2015.

30. Schrödinger Release 2015-2: Maestro, version 10.2, Schrödinger, LLC, New York, NY, 2015.

31. Cho YY, Yao K, Kim HG, Kang BS, Zheng D, Bode AM and Dong Z: Ribosomal S6 kinase 2 is a key regulator in tumor promoter induced cell transformation. Cancer Res 67: 8104-8112, 2007.

32. Li B, Huang G, Zhang X, Li R, Wang J, Dong Z and He Z: Increased phosphorylation of histone H3 at serine 10 is involved in Epstein-Barr virus latent membrane protein-1-induced carcinogenesis of nasopharyngeal carcinoma. BMC Cancer 13: 124, 2013. 
33. Malakhova M, Kurinov I, Liu K, Zheng D, D'Angelo I, Shim JH, Steinman V, Bode AM and Dong Z: Structural diversity of the active $\mathrm{N}$-terminal kinase domain of p90 ribosomal S6 kinase 2. PLoS One 4: e8044, 2009.

34. Pearce LR, Komander D and Alessi DR: The nuts and bolts of AGC protein kinases. Nat Rev Mol Cell Biol 11: 9-22, 2010.

35. Sassone-Corsi P, Mizzen CA, Cheung P, Crosio C, Monaco L, Jacquot S, Hanauer A and Allis CD: Requirement of Rsk-2 for epidermal growth factor-activated phosphorylation of histone $\mathrm{H} 3$. Science 285: 886-891, 1999.

36. Karin M, Liu Z and Zandi E: AP-1 function and regulation. Curr Opin Cell Biol 9: 240-246, 1997.

37. Cho YY: RSK2 and its binding partners in cell proliferation, transformation and cancer development. Arch Pharm Res 40: 291-303, 2017.

38. David JP, Mehic D, Bakiri L, Schilling AF, Mandic V, Priemel M, Idarraga MH, Reschke MO, Hoffmann O, Amling M,et al: Essential role of RSK2 in c-Fos-dependent osteosarcoma development. J Clin Invest 115: 664-672, 2005.

39. Sulzmaier FJ, Young-Robbins S, Jiang P, Geerts D, Prechtl AM, Matter ML, Kesari S and Ramos JW: RSK2 activity mediates glioblastoma invasiveness and is a potential target for new therapeutics. Oncotarget 7: 79869-79884, 2016.

40. Shimura Y, Kuroda J, Ri M, Nagoshi H, Yamamoto-Sugitani M, Kobayashi T, Kiyota M, Nakayama R, Mizutani S, Chinen Y, et al: $\mathrm{RSK} 2^{\mathrm{Ser} 227}$ at N-terminal kinase domain is a potential therapeutic target for multiple myeloma. Mol Cancer Ther 11: 2600-2609, 2012.

41. Cho YY, Lee MH, Lee CJ, Yao K, Lee HS, Bode AM and Dong Z: RSK2 as a key regulator in human skin cancer. Carcinogenesis 33: 2529-2537, 2012.

42. Roessler S, Jia HL, Budhu A, Forgues M, Ye QH, Lee JS, Thorgeirsson SS, Sun Z, Tang ZY, Qin LX, et al: A unique metastasis gene signature enables prediction of tumor relapse in early-stage hepatocellular carcinoma patients. Cancer Res 70: 10202-10212, 2010.

43. Kuete V and Sandjo LP: Isobavachalcone: An overview. Chin J Integr Med 18: 543-547, 2012.

44. Akihisa T, Tokuda H, Hasegawa D, Ukiya M, Kimura Y, Enjo F, Suzuki T and Nishino H: Chalcones and other compounds from the exudates of Angelica keiskei and their cancer chemopreventive effects. J Nat Prod 69: 38-42, 2006.
45. Nishimura R, Tabata K, Arakawa M, Ito Y, Kimura Y, Akihisa T, Nagai H, Sakuma A, Kohno H and Suzuki T: Isobavachalcone, a chalcone constituent of Angelica keiskei, induces apoptosis in neuroblastoma. Biol Pharm Bull 30: 1878-1883, 2007.

46. Jing H, Zhou X, Dong X, Cao J, Zhu H, Lou J, Hu Y, He Q and Yang B: Abrogation of Akt signaling by Isobavachalcone contributes to its anti-proliferative effects towards human cancer cells. Cancer Lett 294: 167-177, 2010.

47. Feng J, Tamaskovic R, Yang Z, Brazil DP, Merlo A, Hess D and Hemmings BA: Stabilization of Mdm2 via decreased ubiquitination is mediated by protein kinase B/Akt-dependent phosphorylation. J Biol Chem 279: 35510-35517, 2004.

48. Qiu Q, Jiang J, Lin L, Cheng S, Xin D, Jiang W, Shen J and Hu Z: Downregulation of RSK2 influences the biological activities of human osteosarcoma cells through inactivating AKT/mTOR signaling pathways. Int J Oncol 48: 2508-2520, 2016.

49. Cho YY, He Z, Zhang Y, Choi HS, Zhu F, Choi BY, Kang BS, Ma WY, Bode AM and Dong Z: The p53 protein is a novel substrate of ribosomal S6 kinase 2 and a critical intermediary for ribosomal S6 kinase 2 and histone $\mathrm{H} 3$ interaction. Cancer Res 65: 3596-3603, 2005.

50. She QB, Ma WY, Zhong S and Dong Z: Activation of JNK1, RSK2, and MSK1 is involved in serine 112 phosphorylation of bad by ultraviolet B radiation. J Biol Chem 277: 24039-24048, 2002.

51. Anjum R, Roux PP, Ballif BA, Gygi SP and Blenis J: The tumor suppressor DAP kinase is a target of RSK-mediated survival signaling. Curr Biol 15: 1762-1767, 2005.

52. Chen KF, Lin JP, Shiau CW, Tai WT, Liu CY, Yu HC, Chen PJ and Cheng AL: Inhibition of Bcl-2 improves effect of LCL161, a SMAC mimetic, in hepatocellular carcinoma cells. Biochem Pharmacol 84: 268-277, 2012.

53. Jiang L, Zhang Q, Ren H, Ma S, Lu C, Liu B, Liu J, Liang J, Li M and Zhu R: Dihydromyricetin enhances the chemo-sensitivity of nedaplatin via regulation of the $\mathrm{p} 53 / \mathrm{Bcl}-2$ pathway in hepatocellular carcinoma Cells. PLoS One 10: e0124994, 2015. 